\title{
Degradation mechanism analysis in temperature stress tests on III-V ultra-high concentrator solar cells using a 3D distributed model
}

\author{
P. Espinet ${ }^{a, *}$, C. Algora ${ }^{a}$, J.R. González ${ }^{a}$, N. Núnez ${ }^{\text {a,b }}$, M. Vázquez ${ }^{\text {a,b }}$ \\ ${ }^{a}$ Instituto de Energía Solar - Universidad Politécnica de Madrid, E.T.S.I Telecomunicación, Avda. Complutense 30, 28040 Madrid, Spain \\ ${ }^{b}$ EUIT de Telecomunicación, Campus Sur-UPM, Km. 7 Carretera de Valencia, 28031, Madrid, Spain
}

\section{Introduction}

High-concentration photovoltaic (CPV) systems seem to be one of the most promising ways to generate electricity at competitive prices for terrestrial applications [1]. In the past decade, the efficiency of multi-junction solar cells has increased considerably [25]. Nevertheless, the CPV community is aware that, together with the efficiency increase, high reliability is essential for reducing the cost of solar electricity by extending the system's lifetime [6]. Silicon modules are reliable systems that have performed well in the field with less than $1 \%$ degradation/year for more than 20 years [7]. However, the knowledge of the reliability of III-V solar cells is still scarce [8-12]. This work identifies the failure mechanism in an accelerated temperature stress test carried out on GaAs solar cells in order to improve the quality of these devices. The aim of this work was to analyze the failure mechanism of this kind of solar cell using a 3D distributed model based on elemental circuit units [13]. In this article, we show the potential of the 3D distributed model in the evaluation of degradation in III-V solar cells.

\section{Experimental}

\subsection{Assembly description}

The assembly of the solar cells used in this test presented the following characteristics: (a) encapsulation on direct-bonded

\footnotetext{
* Corresponding author.

E-mail address: pespinet@ies-def.upm.es (P. Espinet).
}

copper (DBC) substrates improved the thermal dissipation, (b) encapsulated cells were attached to an aluminum box with a thermal-conductive adhesive, and (c) cells were covered with silicone to simulate a real situation of the solar cell inside the secondary optics in a concentrator.

\subsection{Test methodology}

The acceleration of the degradation was performed by means of temperature stressing. Two sets of 18 solar cells were placed inside climatic chambers at different temperatures of 130 and $150{ }^{\circ} \mathrm{C}$. Because the solar cells inside the climatic chambers were in darkness, the current mainly flowed vertically beneath the busbar [13]. The area of the busbar was $0.64 \mathrm{~mm}^{2}$. Therefore, assuming that the short circuit density current of this kind of solar cell is $25 \mathrm{~mA}$ / $\mathrm{cm}^{2}$ at $1 \times$, working conditions at $700 \times$ were simulated by injecting $112 \mathrm{~mA}$ into each solar cell. A detailed description of the accelerated test can be found elsewhere [14].

\section{3D distributed model}

\subsection{Model description}

An explanation of the degradation mechanism in degraded solar cells is presented in this paper using a 3D network model. The philosophy of the 3D distributed model has been explained in detail elsewhere [13]. This approach divides the solar cell into elementary units and assigns each unit to a suitable circuit model, depending on its geometry and position in the solar cell: illumination, dark 
and perimeter (Figs. 1 and 2). The complete solar cell is modeled by the electrical circuit obtained by interconnecting every unit cell with its neighbor. The resulting equivalent circuit formed by thousands of elements is resolved using the SPICE circuit simulator. The fitness of this model for the analysis of the degradation mechanism is derived from the treatment of the loss effects in a distributed manner.

For the ohmic losses, a set of resistors modeling the different series resistance components was used (front grid, semiconductor layers; front and back contacts, substrate). Regarding the recombination phenomena, three diodes were used to model the recombination in the neutral regions (ideality factor $n_{1}=1$ ), in the depletion regions (ideality factor $n_{2}=2$ ) and at the perimeter (ideality factor $n_{2 \text { PER }}=2$ ). It is important to note that a reasonable fit between experimental measurements and simulations can be achieved using other ideality factors. However, the parameters $J_{01}, J_{02}$ and $J_{02 \text { PER }}$ obtained from such a strategy are mathematical parameters that lack a direct physical meaning. The extension of this model to multi-junction solar cells including tunnel junction description has been already done [15].

\subsection{Explanation for the dark I-V curve in GaAs solar cells}

Simulations of a typical GaAs solar cell varying the values of more relevant parameters in the dark $I-V$ curve were carried out to obtain a better understanding of the results presented in Section 4.

The effect of series resistances is observed at high voltages. In the $I-V$ curve, the lateral resistances such as the emitter sheet

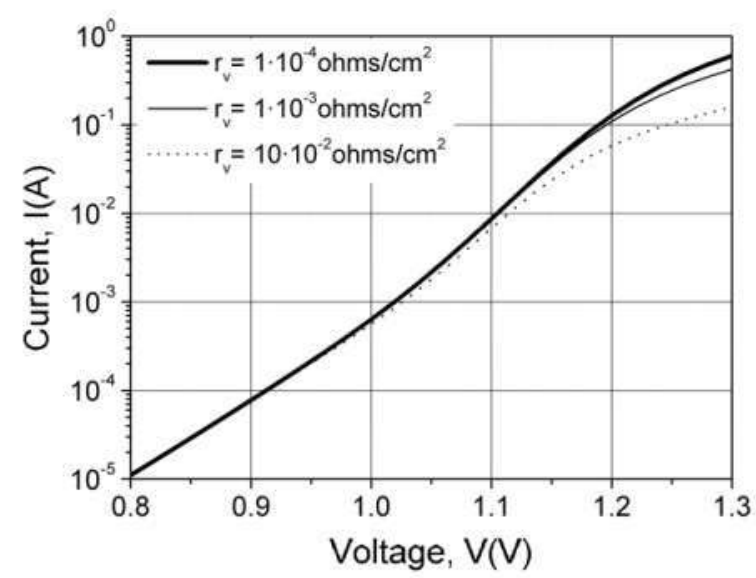

Fig. 3. Variations of the vertical resistance $\left(r_{\mathrm{V}}\right)$, which take into account the resistance at the base, in the BSF layer and in the back contact.

resistance $\left(r_{\mathrm{E}}\right)$, the base sheet resistance $\left(r_{\mathrm{B}}\right)$ and the metal sheet resistance $\left(r_{M}\right)$ have a negligible impact on the curve because the current mainly flows vertically beneath the busbar [13]. On the other hand, both the vertical resistance $\left(r_{\mathrm{V}}\right)$ and the front grid specific contact resistance $\left(r_{\mathrm{FC}}\right)$ show a large influence under dark conditions (see Fig. 3). However, the effect of the shunt resistances at the bulk $\left(r_{\mathrm{p}}\right)$ or at the perimeter $\left(r_{\mathrm{pPER}}\right)$ is observed at low voltages (see Fig. 4). Previous studies of the degradation in GaAs solar cells without perimeter isolation revealed changes in the shunt resistance at the perimeter [8].

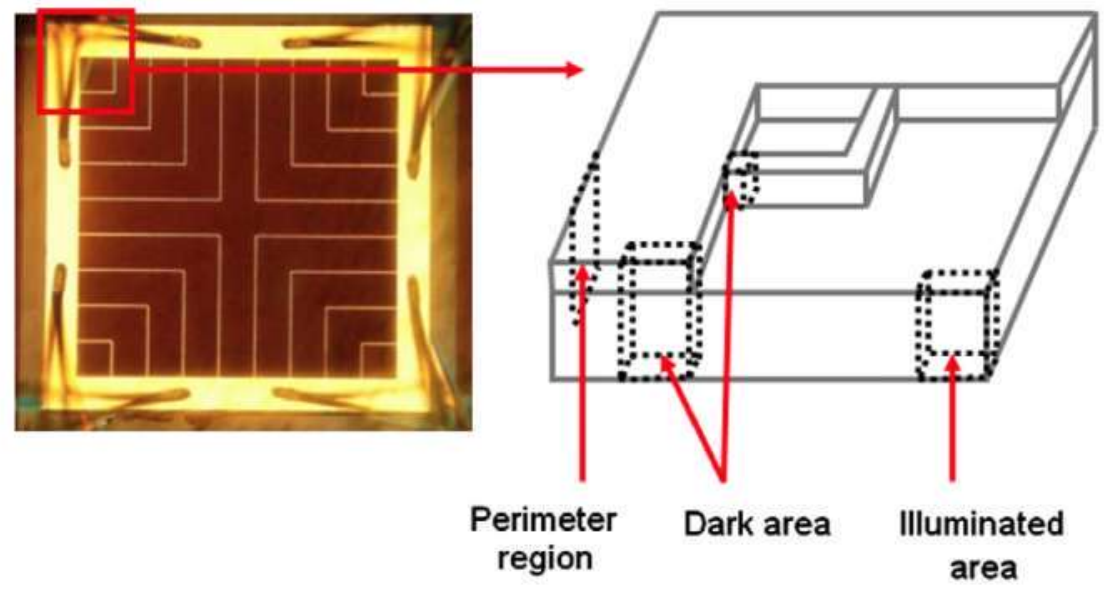

Fig. 1. 3D network model for a single-junction solar cell.
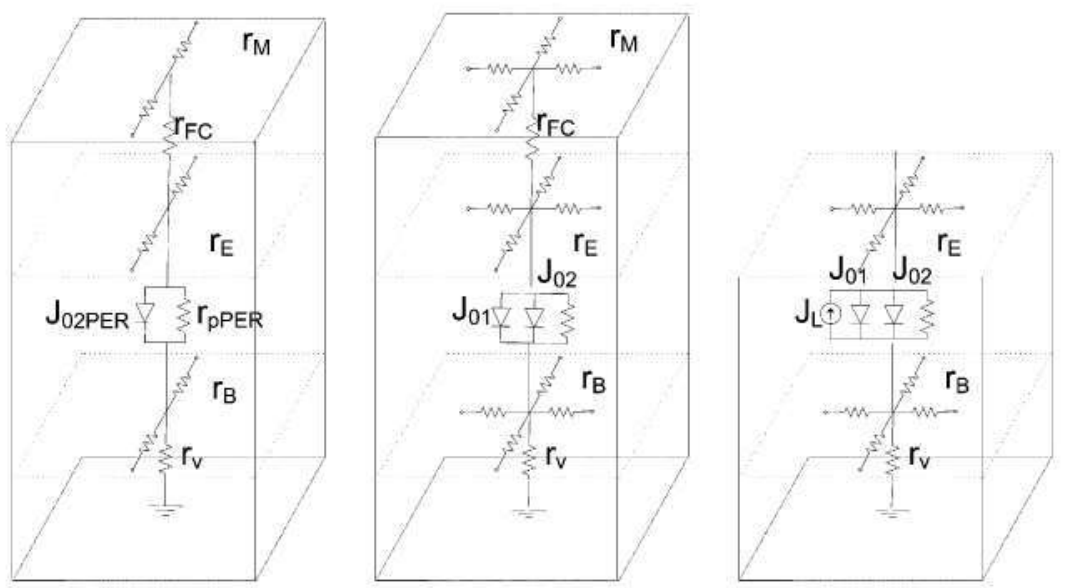

Fig. 2. From left to right, the elementary unit cell of the perimeter area, dark area and illuminated area. A detailed description can be found in [13]. 


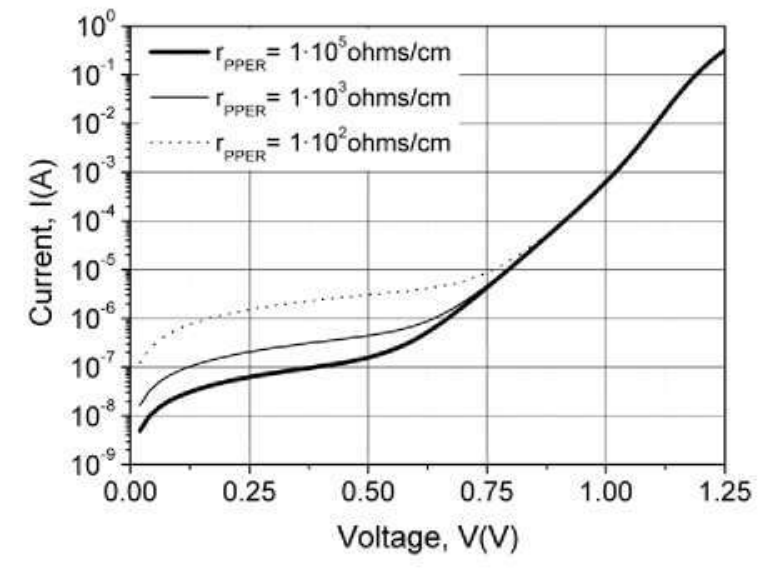

Fig. 4. Variations of the shunt resistance in the perimeter region $\left(r_{\mathrm{PPER}}\right)$.

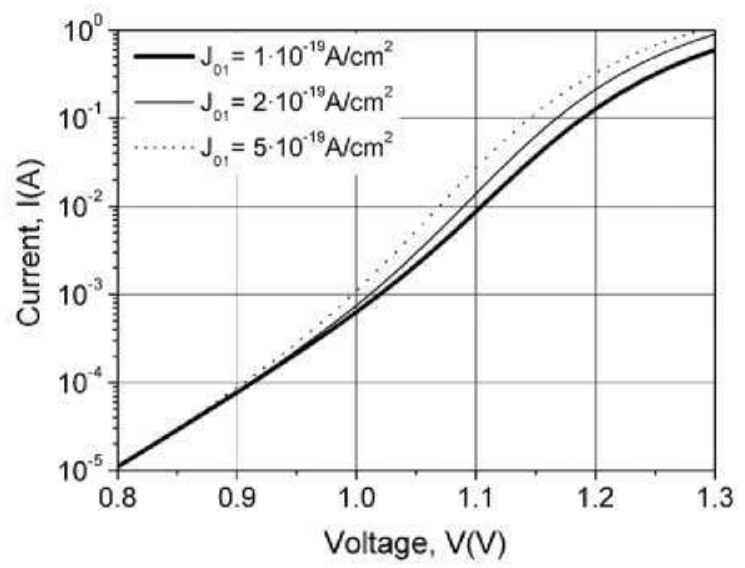

Fig. 5. Variations of the recombination current density in the neutral regions $\left(J_{01}\right)$.

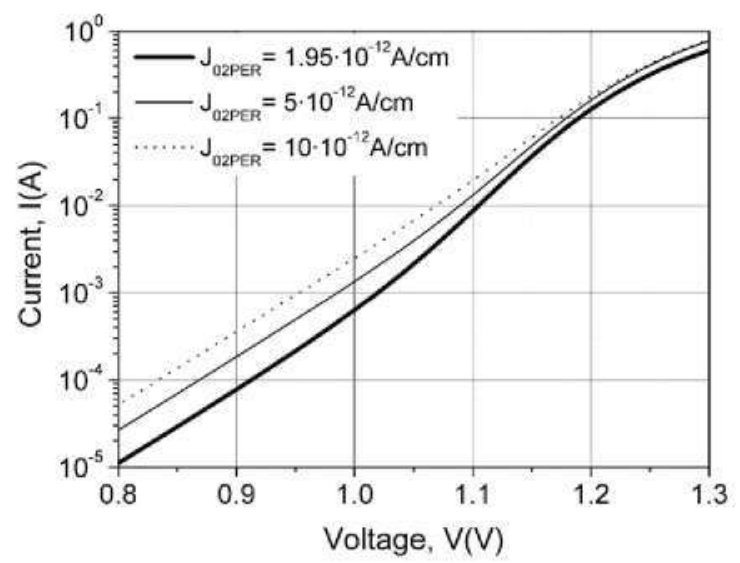

Fig. 6. Variations of the recombination current density at the perimeter ( Jo2PER$_{\text {) }}$.

The parameter $J_{01}$ takes into account the recombination at the neutral regions. The main influence of this parameter occurs at high voltages (Figs. 5 and 6 ).

The parameters $J_{02 \mathrm{PER}}$ and $J_{02}$ both have an effect at low voltages; however, several studies in GaAs [16-19] show that the amplitude of the recombination current with ideality factor $n=2$ does not correlate with the area; instead, it correlates with the perimeter. A previous study of degradation in GaAs solar cells revealed changes in the $I-V$ curve at low voltages [8]; consequently, a study of the perimeter recombination in our growth material and our technology was essential. Circular diodes of GaAs with four different sizes (Table 1) were processed to study the recombination mechanism at low voltages.

In Figs. 7-9, the dark $I-V$ curve, the $J-V$ curve and the lineal density current at the perimeter versus voltage are depicted, respectively, for representative examples of a large number of diodes for each size. From these figures it can be inferred that, as expected, at low voltages the current correlates with the area in agreement with Refs. [16-19]. Therefore, $I_{02}$ is smaller than $I_{02 \text { PER, }}$ and its influence is negligible.

\section{Results}

In all cases tested, only gradual failures were observed, and the degradation trend was the same for the two groups of solar cells tested at different temperatures. Therefore, the same failure mech-

Table 1

Dimensions of the diodes of GaAs used in the study of the recombination current at low voltages.

\begin{tabular}{lll}
\hline Diode & Area $\left(\mathrm{mm}^{2}\right)$ & Perimeter $(\mathrm{mm})$ \\
\hline A & 7 & 9.4 \\
B & 1.8 & 4.7 \\
C & 0.4 & 2.3 \\
D & 0.1 & 1.1 \\
\hline
\end{tabular}

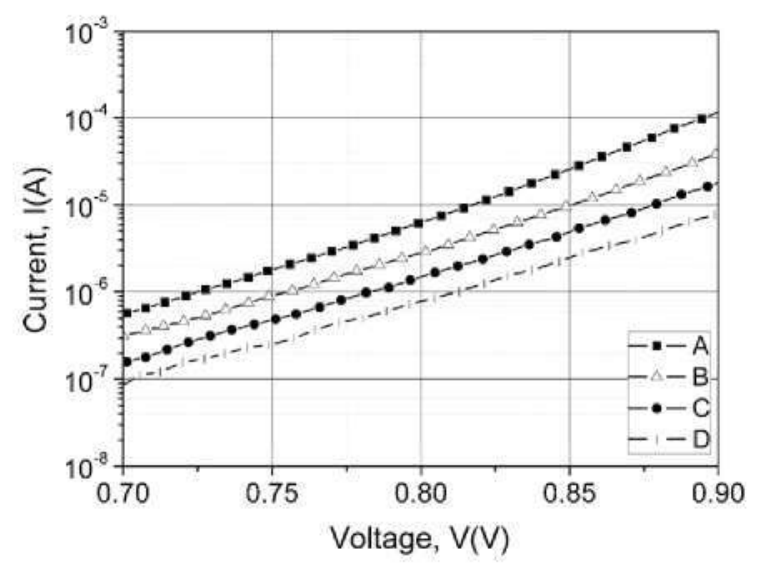

Fig. 7. Dark $I-V$ curves of the GaAs diodes of different sizes.

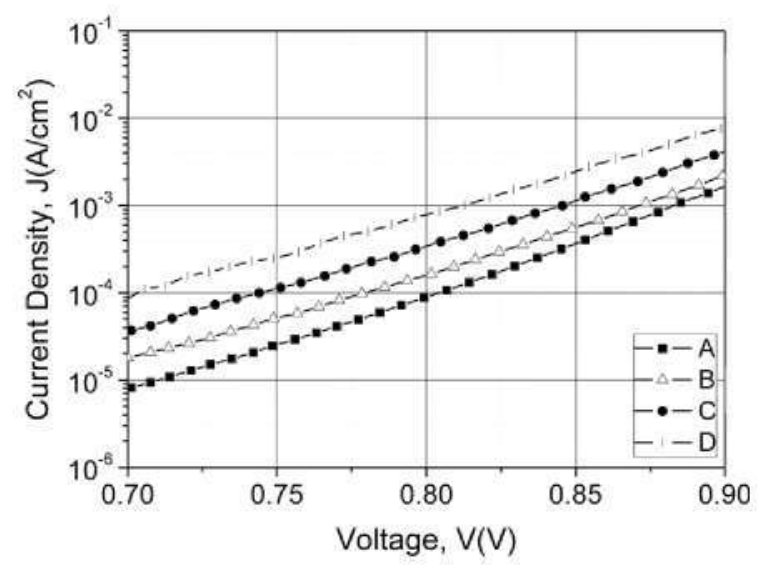

Fig. 8. Dark $J-V$ curves of the GaAs diodes of different sizes. 


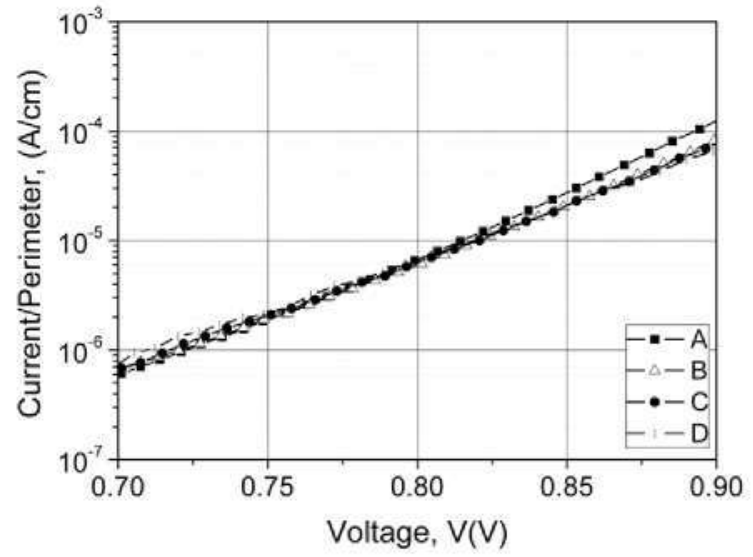

Fig. 9. Linear current density $(I / P)$ versus voltage of the GaAs diodes of different sizes.

anism was responsible for the degradation in all of the solar cells. To analyze the degradation mechanism, different fits with the 3D distributed model explained in Section 3 were carried out at $25^{\circ} \mathrm{C}$ before and after the test. Fig. 10 is a representative case of the 18 solar cells studied at each temperature. An accurate description of the GaAs solar cell before and after degradation was obtained with the 3D distributed model.

The parameters used in the fits of Fig. 10 are presented in Table 2.

Using Table 2, we can conclude that the solar cells degraded in the perimeter region because the recombination current density in the depletion region at the perimeter $\left(J_{02 \mathrm{PER}}\right)$ is the only parameter that changed in the fits. After the accelerated test at $130^{\circ} \mathrm{C}, J_{02 P E R}$ was almost fourfold higher than before the test. Even though the perimeter was passivated with silicone, it seems to be the most fragile part of the solar cell; the current flowing beneath the busbar favors the progression of defects in the device perimeter and thus causes an increase in the dark current. Hence, because the perimeter is not passivated, the gradual degradation in GaAs solar cells might proceed as follows [20]: (1) non-radiative ( $n=2)$ recombination occurs at some defects at the perimeter, which causes a point defect reaction and fresh point defect generation and (2) the new defects also act as non-radiative recombination centers, and thus this process increases the J02PER. Also, the silicone caused thermal oxidative degradation after the test. Therefore, the oxidation of the organic groups and degradation of the main chain of the molecule can have an effect on the unpassivated perimeter.

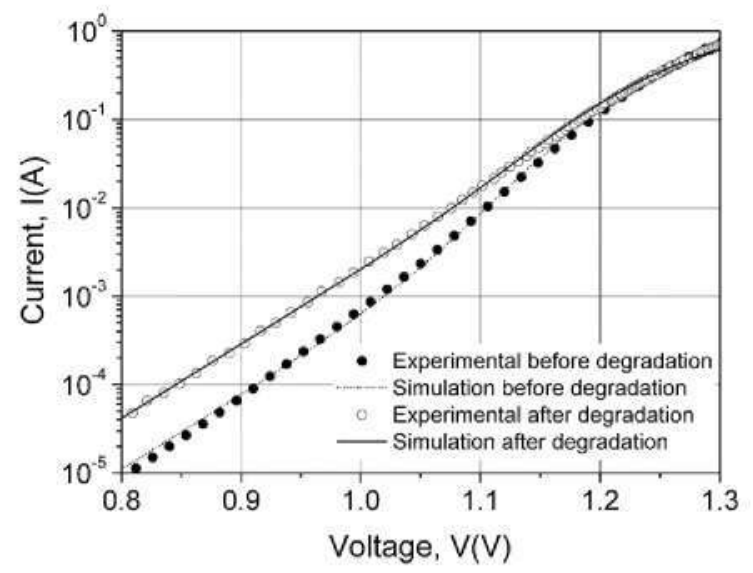

Fig. 10. Measured dark $I-V$ curve of the solar cell before (black circles) and after (white triangles) the accelerated degradation test. Fit with the 3D distributed model before (dotted line) and after the test (solid line).
Table 2

Parameters used in the fits of Fig. 9.

\begin{tabular}{lll}
\hline Parameter & Before & After \\
\hline$J_{O 1}\left(\mathrm{~A} / \mathrm{cm}^{2}\right)$ & $1 \times 10^{-19}$ & $1 \times 10^{-19}$ \\
$J_{O 2}\left(\mathrm{~A} / \mathrm{cm}^{2}\right)$ & $1 \times 10^{-11}$ & $1 \times 10^{-11}$ \\
$J_{O 2 \text { PER }}(\mathrm{A} / \mathrm{cm})$ & $1.95 \times 10^{-12}$ & $8 \times 10^{-12}$ \\
$r_{\mathrm{FC}}\left(\Omega \mathrm{cm}^{2}\right)$ & $2 \times 10^{-4}$ & $2 \times 10^{-4}$ \\
$r_{\mathrm{V}}\left(\Omega \mathrm{cm}^{2}\right)$ & $1 \times 10^{-4}$ & $1 \times 10^{-4}$ \\
$r_{\mathrm{p}}\left(\Omega \mathrm{cm}^{2}\right)$ & $1 \times 10^{5}$ & $1 \times 10^{5}$ \\
$r_{\mathrm{pPER}}(\Omega \mathrm{cm})$ & $1 \times 10^{5}$ & $1 \times 10^{5}$ \\
$r_{\mathrm{E}}(\Omega \square)$ & 200 & 200 \\
$r_{\mathrm{B}}(\Omega \square)$ & 600 & 600 \\
$r_{\mathrm{M}}(\Omega \square)$ & 0.2 & 0.2 \\
\hline
\end{tabular}

Note that a satisfactory fit could be achieved by varying the $J_{02}$ parameter and fixing $J_{02 \text { PER }}$ or by modifying both parameters. Therefore, a previous understanding of the device is necessary to obtain a physically significant fit.

The increase in saturation current at the perimeter leads to a decrease in the fill factor and the open circuit voltage, resulting in a slight decrease of efficiency. However, it has to be mentioned that the relative decrease in power would be more prominent in applications with lower concentration.

Finally it must be pointed out that this test did not cause any morphological changes in the devices.

\section{Conclusions}

In this paper, the failure mechanism in temperature stress testing of GaAs solar cells according to a 3D distribution model was studied. Fits of the $I-V$ curve at $25^{\circ} \mathrm{C}$ with the $3 \mathrm{D}$ distributed model before and after degradation were done. An accurate description of the solar cell before and after degradation was obtained with the model. Furthermore, the model revealed that the degradation takes place in the perimeter region because the recombination current density at the perimeter increased by a factor of 4 . Results of this study confirm that GaAs concentrator solar cells are resistant devices because neither catastrophic failures nor morphological changes occurred.

\section{Acknowledgments}

This work was supported by the Spanish Ministerio de Educación y Ciencia with the CONSOLIDER-INGENIO 2010 program by means of the GENESIS FV Project (CSD2006-004). The Spanish Ministerio de Ciencia e Innovación has also contributed with the SIGMASOLES Project (PSS-440000-2009-30) and with the project with reference TEC2008-01226 as well as the Comunidad de Madrid under the NUMANCIA II programme (S2009/ENE1477).

\section{References}

[1] Yamaguchi M, Luque A. IEE Trans Electron Dev 1999;46:2139-44.

[2] García I, Rey-Stolle I, Galiana B, Algora C. Appl Phys Lett 2009;94:053509.

[3] Geisz JF, Friedman DJ, Ward JS, Duda A, Olavarria WJ, Moriarty TE, et al. Appl Phys Lett 2008;93:123505.

[4] Guter W, Schone J, Philipps SP, Steiner M, Siefer G, Wekkeli A, et al. Appl Phys Lett 2009:94:223504.

[5] King RR, Law DC, Edmondson KM, Fetzer CM, Kinsey GS, Yoon H, et al. Appl Phys Lett 2007;90:183516.

[6] Kurtz JGS, Quintana M. Society of photographic instrumentation engineers (SPIE), San Diego, California (USA); 2009.

[7] Osterwald JACR, del Cueto JA, Korposki B, Trudell D, Moriarty T. In: 32nd IEEE photovoltaic specialist conference; 2006. p. 2085-8.

[8] Gonzalez JR, Vazquez M, Nunez N, Algora C, Rey-Stolle I, Galiana B. Microelectron Reliab 2009;49(July):673-80.

[9] Rey-Stolle I, Algora C. Prog Photovoltaics 2003;11(June):249-54.

[10] Schöne GP], Hoheisel R, Siefer G, Guter W, Dimroth F, Bett AW. In: 23rd European photovoltaic conference and exhibition, Valencia (Spain); 2008.

[11] Araki HUK, Kondo M, Takamoto T, Agui T, Kaneiwa M, Egami T, et al. In: 31 rd IEEE photovoltaic specialist conference Lake Buena Vista, Florida (USA); 2005 
[12] yan Riesen S. Bett AW. Prog Photovoltaics 2005;13(August):369-80.

[13] Galiana B, Algora C, Rey-Stolle l. Prog Photovoltaics 2008;16:331-8.

[14] Núnez N, Vázquez M, González JR, Algora C. Espinet P. In: ESREF; 2010

[15] Espinet $\mathrm{P}$, García I, Rey-Stolle I, Algora C, Baudrit M. In: Proceedings of the international conference on concentrating photovoltaic CPV6. Freibur (Germany); 2010 .
|16| Henry CH, logan RA, Merritt FR. J Appl Phys 1978;49(6):3530-42.

17] Mazhari B, Morkoc H. J Appl Phys 1993;73(11):7509-14.

|18| Belgachi A. Microelectron J 2005(36):115-24.

[19] DeMoulin PD, Tobin SP, Lundstrom MS, Carpenter MS, Melloch MR. IEEE Electron Dev lett 1988:9:368-70.

[20] Ueda 0. Microelectron Reliab 1999;39(12):1839-55. 